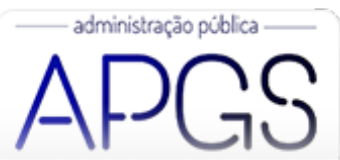

Administração Pública e Gestão Social ISSN: 2175-5787

apgs@ufv.br

Universidade Federal de Viçosa

Brasil

\title{
O conceito de gestão social e a democracia regressiva no Brasil após 2016
}

Tenorio, Fernando Guilherme; Carvalho Teixeira, Marco Antônio

O conceito de gestão social e a democracia regressiva no Brasil após 2016

Administração Pública e Gestão Social, vol. 13, núm. 2, 2021

Universidade Federal de Viçosa, Brasil

Disponible en: http://www.redalyc.org/articulo.oa?id=351566014011

\section{(c) $(1) \Theta \theta$}

Esta obra está bajo una Licencia Creative Commons Atribución-NoComercial-SinDerivar 3.0 Internacional. 


\title{
O conceito de gestão social e a democracia regressiva no Brasil após 2016
}

\author{
Fernando Guilherme Tenorio \\ Escola Brasileira de Administração Pública e de Empresas \\ da FGV, Brasil \\ fernando.tenorio@fgv.br \\ Marco Antônio Carvalho Teixeira \\ Escola de Administração de Empresas da Fundação Getulio \\ Vargas de São Paulo (FGVEAESP), Brasil \\ marco.teixeira@fgv.br
}

The concept of social management and regressive democracy in post-2016 Brazil

El concepto de gestión social y democracia regresiva en Brasil después de 2016

Redalyc: http://www.redalyc.org/articulo.oa?

Recepción: 13 Julio 2020

Aprobación: 08 Septiembre 2020

Publicación: 01 Abril 2021

\section{Resumo:}

Objetivo da pesquisa: O presente texto tem o objetivo de contextualizar o debate sobre gestão social no Brasil, verificando até que ponto a incerteza acerca do futuro da democracia pode apoiar ou impedir a prática de uma gestão comprometida com a sociedade. Enquadramento teórico: A Constituição de 1988 ficou próxima da gestão social na medida em que o postulado da democracia brasileira superou os ciclos eleitorais e incorporou arenas participativas como espaços de compartilhamentos de decisões públicas em interação com as diferentes instâncias legislativas e executivas e os órgãos do aparato burocrático nos diversos níveis de governo. Todavia, em 2016 o contexto institucional foi alterado, colocando dúvidas acerca da possibilidade de práticas gerenciais democráticas.

Metodologia: Para a realização deste trabalho mobilizamos uma extensa revisão bibliográfica sobre o desenvolvimento do conceito de gestão social e, por meio do registro de momentos históricos, analisamos o debate sobre a gestão social no Brasil, sobretudo desde 1988 até o tempo presente.

Resultados: Ao cotejarmos a política brasileira após 2016 com o conceito de gestão social, evidenciou-se um hiato. Identificase uma clara tentativa de extinguir espaços democráticos ou mesmo sufocá-los. Estamos ainda diante de um retrato e não vislumbramos qual será o final deste filme.

Originalidade: $O$ presente trabalho é inédito por colocar em diálogo o conceito de gestão social desde os princípios democratizantes de 1988 à regressividade democrática em curso no Brasil e como isso afeta diretamente a perspectiva de uma gestão efetivamente social.

Contribuições teóricas e práticas: A contribuição é de caráter interdisciplinar e dialoga diretamente com os debates sobre gestão e participação social, mas também acerca do futuro do conceito de gestão social no Brasil em tempos de incertezas sobre a democracia. Palavras-ChaVE: Constituição, gestão social, gestão estratégica e participação cidadã.

\section{ABstract:}

Research objective: This text aims to contextualize the debate on social management in Brazil, analyzing the extent to which the uncertainty about the future of democracy can either support or hinder the practice of a socially committed management.

Theoretical framework: The 1988 Brazilian Constitution was close to social management insofar as the postulate of Brazilian democracy overcame electoral cycles and incorporated participatory arenas as spaces for sharing public decisions in interaction with the different legislative and executive bodies and the bureaucratic organs in the different levels of government. However, in 2016 the institutional context was changed, casting doubt on the possibility of democratic managerial practices.

Methodology: To carry out this work, we conducted an extensive literature review on the development of the concept of social management and, through the recording of historical moments, we analyzed the debate on social management in Brazil, especially after 1988 until the present time.

Results: With this study, it was possible to notice that there is a gap between the post-2016 Brazilian policy and the concept of social management. In fact, there is a clear attempt to extinguish democratic spaces and even suffocate it. We are still looking at a portrait of this scenario and we do not see what the end of this film will be. 
Originality: The present work is unprecedented as it presents the concept of social management since its democratizing principles in 1988 until the democratic regressiveness underway in Brazil and how it directly affects the perspective of an effectively social management.

Theoretical and practical contributions: The contribution of this paper is interdisciplinary as it dialogues directly with the debates on management and social participation. It also sheds light on the future of the concept of social management in Brazil in times of uncertainty about the future of democracy.

KEYWORDS: Constitution, Social management, Strategic management, Citizen participation.

\section{RESUMEN:}

Objetivo de la investigación: Este texto tiene como objetivo contextualizar el debate sobre la gestión social en Brasil, verificando hasta qué punto la incertidumbre sobre el futuro de la democracia puede apoyar o impedir la práctica de una gestión comprometida con la sociedad.

Marco teórico: La Constitución de 1988 acercó a la gestión social en la medida en que el postulado de la democracia brasileña superó los ciclos electorales e incorporó arenas participativas como espacios de intercambio de decisiones públicas en interacción con los diferentes órganos legislativos y ejecutivos y los órganos burocráticos en los diferentes niveles de gobierno. Sin embargo, en 2016 se modificó el contexto institucional, lo que generó dudas sobre la posibilidad de prácticas de gestión democráticas.

Metodología: Para llevar a cabo este trabajo, movilizamos una extensa revisión bibliográfica sobre el desarrollo del concepto de gestión social y, a través del registro de momentos históricos, analizamos el debate sobre la gestión social en Brasil, especialmente desde el año 1988 hasta la actualidad.

Resultados: Al comparar la política brasileña posterior a 2016 con el concepto de gestión social, se hizo evidente una pausa. Hay un claro intento de extinguir los espacios democráticos o incluso asfixiarlos. Seguimos ante un retrato y no vemos cuál será el final de esta película.

Originalidad: El presente trabajo es inédito por poner en diálogo el concepto de gestión social desde los principios democratizadores de 1988 hasta la regresividad democrática en marcha en Brasil y cómo afecta directamente la perspectiva de una gestión social eficaz.

Contribuciones teóricas y prácticas: La contribución es interdisciplinar y dialoga directamente con los debates sobre gestión y participación social, pero también sobre el futuro del concepto de gestión social en Brasil en tiempos de incertidumbre sobre la democracia.

Palabras clave: Constitución, gestión social, gestión estratégica y participación ciudadana.

\section{INTRODUÇÃO}

Seríamos atemporais e anti-históricos se acreditássemos na inviolabilidade dos conceitos e, dada a especificidade deste texto, do conceito de gestão social tal qual defendemos desde o início dos anos 1990. Desde então, apregoamos o conceito de gestão social ${ }^{[i]}$ como um modo gerencial que deveria ser coetâneo das demandas de uma sociedade mais justa, plural e determinante de seus anseios, um modo antinômico ao conceito de gestão estratégica,[ii] coetâneo das demandas específicas do mercado, sob a égide do neoliberalismo, no qual o valor de troca predomina sobre o valor de uso.

No caso brasileiro, o contexto da possibilidade dessa antinomia começa a ser institucionalmente definido por meio dos preceitos constitucionais de 1988. Vale relembrar que a Constituição Federal de 1988, que ficou conhecida como "Constituição cidadã", define de imediato no seu Título I e nos seus Princípios Fundamentais o art. 1., que diz:

A República Federativa do Brasil, formada pela união indissolúvel dos Estados e Municípios e do Distrito Federal, constitui-se em Estado Democrático de Direito e tem como fundamentos:

I - a soberania;

II - a cidadania;

III - a dignidade da pessoa humana;

IV - os valores sociais do trabalho e da livre iniciativa;

$\mathrm{V}$ - o pluralismo político. 
Parágrafo único. Todo o poder emana do povo, que o exerce por meio de representantes eleitos ou diretamente, nos termos desta Constituição (Brasil, Constituição, 1988, p. 3).

Desse art. 1. destacamos dois itens fundamentais para legitimar o conceito de gestão pretendido: II cidadania e o Parágrafo único, apresentando o fato de o poder ser exercido também diretamente pelo povo, ou seja, a Constituição de 1988 possibilita que os processos de tomada de decisão, de quaisquer naturezas, possam ser exercidos pela cidadania de forma direta, e não exclusivamente por meio de seus representantes eleitos. O importante desse Parágrafo único é que, a partir de então, o país passou a discutir a possibilidade não só da democracia representativa, mas também da democracia deliberativa. Essa democracia favorece a participação cidadã por meio de um modo decisório dialógico, fundamental à implementação de um procedimento gerencial, a gestão social, que preconiza a participação de todos os concernidos, afetados em qualquer processo de tomada de decisão.

Alguns dirão ser uma pretensão utópica, no entanto, diante da distopia em que vivemos, a utopia gênese deste texto, a gestão social, estaria fundamentada no princípio da esperança preconizado por Ernst Bloch, no qual o ato de pensar significa transpor o existente. E o que concretamente existe? Um modo de administrar, a gestão estratégica, aquém da possibilidade de uma sociedade republicana, socialmente justa. Acompanhando o pensamento de Bloch, desde a Constituinte de 1988 a sociedade brasileira está repleta "de disposição para algo, tendência para algo, latência de algo" (Bloch, 2005, p. 28), de ter o controle social do seu destino daí a necessidade de um modo organizativo que dê suporte a esse desejo participativo por meio de outro tipo de gestão, que aqui defendemos, uma gestão social comunitariamente organizada. Na realidade, "trata[se] do que poderíamos denominar o princípio de incompletude histórica, que deixa aberta a possibilidade da inovação, a ruptura e a quebra, em outras palavras" (Linera, 2015, p. 11), de mudança conceitual que radicalize alterando o modo gerencial do pensar hegemônico contemporâneo. Dessa maneira, a proposta de uma gestão dialógica compartilhada com os diferentes atores da sociedade está apoiada no princípio da esperança blochiano, na medida em que a Constituinte de 1988 promoveu a latência de uma sociedade democrática e participativa e, também, fundamentado no princípio de incompletude histórica lineriano, já que a Carta Magna de 1988 ainda deixa em aberto a possibilidade da inovação por meio de um processo gerencial diferenciado do hegemônico.

Desde a Constituição de 1988, o postulado da democracia representativa no Brasil não é mais o mote de uma participação cidadã que ocorria a cada ciclo eleitoral. Embora a soberania popular pudesse ser exercida de forma direta e (ou) participativa em interação com as diferentes instâncias legislativas e executivas e os órgãos do aparato burocrático nos diversos níveis de governo, em 2016 o contexto institucional foi alterado sob uma perspectiva que faz dormitar os preceitos de 1988, deixando em suspenso a possibilidade de práticas gerenciais democráticas.

O presente artigo tem como objetivo central contextualizar o surgimento do conceito de gestão social e verificar até que ponto o momento brasileiro, marcado por um processo de regressão dos avanços democráticos de 1988, em razão do golpe parlamentar de 2016, seguido da eleição de Jair Bolsonaro em 2018 e das incertezas trazidas pela Covid-19 em 2020, têm consequências para uma gestão pública comprometida com a sociedade. $\mathrm{O}$ enfoque analítico recai sobre o contexto do golpe parlamentar. Tal evento deu início a um processo de redução dos espaços democráticos que são caros à construção de uma gestão nos marcos do conceito de gestão social.

\section{GESTÃo SOCIAL: CONTEXTO HISTÓRICO-INSTITUCIONAL}

Sabemos que, em geral, a história institucional de um país é demarcada a partir do início de sua colonização, embora não desconheçamos que o fenômeno da institucionalização possa ocorrer desde o momento em que populações migratórias prévias à colonização passaram a habitar determinado território. Dado o espaço 
disponível e o fato de não ser um artigo com pretensões historiográficas, demarcamos o começo cronológico deste texto a partir da promulgação da Constituição de 1988, portanto 488 anos após o início da colonização brasileira pelos portugueses. Mesmo aceitando o fato de que a Carta Magna de 1988 seja consequência dos séculos que antecederam este final de centúria, não só temos delimitação de espaço para descrever a nossa percepção do objeto de estudo - gestão social - como também acentuar que, no caso brasileiro, essa concepção gerencial procurou vir ao encontro da nossa Lei Máxima logo após sua promulgação. Assim, o contexto institucional do presente artigo será pautado pelos fatos histórico-institucionais ocorridos no entorno do final do século XX e entrante XXI.

Por sua vez, não podemos interpretar questões institucionais dissociadas das questões econômicas, políticas e culturais de um país. $\mathrm{O}$ período no qual ocorre ou não dado fato social está inter-relacionado às circunstâncias desse fato e, como demarcamos o início do presente estudo no entorno de 1988, não podemos esquecer que é no período do governo de José Sarney (1985-1990) que a Constituição é promulgada "entre 1988 e 1999, fundou-se em uma lógica excludente que fomentou a financeirização, a deterioração das condições de vida e de trabalho da maioria e a concentração de renda” (Saad \& Alfredo, 2018, p. 23, itálico dos autores), ou seja, ao nascer, a nova Constituição é submetida ao tacão de uma mediação econômica, liderada pelas históricas elites brasileiras, que não permitem que o outro, a maioria da população, possua direitos que lhes são devidos e que lhes permitam participar de uma melhor distribuição da renda.

Esse período foi ainda agudizado pelo efêmero governo Fernando Collor de Mello (1990-1992), cuja racionalidade econômica neoliberal e promiscuidade administrativa - corrupção - levou-o, para fugir do impeachment, a renunciar em 29 de setembro de 1992. Collor de Mello é substituído em 29 de dezembro pelo vice-presidente Itamar Franco, que completou o período do mandato presidencial até 1. de janeiro de 1995. Apesar de no início dos anos 1990 o conceito de gestão social já ter surgido, ainda não fazia parte da ribalta acadêmica, o que começa a ocorrer quando ele contracena com o conceito de gerência social.

O conceito de gerência social foi exposto em 1992 (19 a 21/08) na cidade de Santa Cruz de la Sierra (Bolívia) no Seminário Iberoamericano de Desarrollo de Profesores en Gerencia Social, organizado pela Red Iberoamericana de Instituciones de Formación en Gerencia Pública (CLAD-AECI/INAP-PNUD). Nesse mesmo evento apresentamos o trabalho "Gestión social: una experiencia de enseñanza e investigación", atividades que desde 1989 vínhamos desenvolvendo na Escola Brasileira de Administração Pública (EBAP) da Fundação Getulio Vargas (FGV). Por sua vez, já em 1993, foi publicado o livro "Pobreza: un tema impostergable. Nuevas respuestas a nível mundial”, organizado por Bernardo Kliksberg e publicado no México pelo Fondo de Cultura Económica, trazendo o conceito de gerência social definido nos capítulos "Gerencia social: dilemas gerenciales y experiencias inovativas", de Kliksberg, e “Como capacitar en gerencia social?: la experiencia del Primer Programa Latinoamericano de Formación de Gerentes Sociales”, de Kliksberg e José Subirats.

Não podemos esquecer que, nesse período, início da década de 1990, de Tijuana (México) até a Isla Hornos (Chile), o modelo econômico sugerido e adotado total ou parcialmente pelos países da América Latina (AL) foi denominado de "Consenso de Washington", sobre o qual uma dúvida ainda persiste: foi realmente uma forma de organização econômico-social acordada entre os países ou uma imposição tecnocrática de orientação neoliberal? A resposta: uma imposição - praticada no Brasil a partir de 1990 com o descontinuado governo de Collor, sequenciada por Itamar Franco e consolidada no governo Fernando Henrique Cardoso, também chamado de FHC (1995 a 2003, em dois mandatos). Nesses períodos as políticas públicas, notadamente as sociais, estavam associadas à concepção de políticas compensatórias. Esse fato foi percebido quando, em 1997, participamos em Washington, D.C. do Curso de Directivos en Diseño y Gestión de Políticas y Programas Sociales nas dependências do Instituto Interamericano para o Desenvolvimento Social (INDES) do BID (Banco Interamericano de Desenvolvimento).

Gerência social era o mote conceitual do gerenciamento de políticas e programas sociais para a América Latina. Nesse curso ficou clara a relação entre gerência social e políticas públicas compensatórias. Em que 
pese a amplitude dos objetivos do curso, que, entre outros assuntos, falava da necessidade de melhorar a articulação entre políticas econômicas e sociais e compreender as inter-relações entre os planos econômico, social e institucional, não cabia dúvida de que o contexto econômico-institucional de então não tinha como agenda atender às questões estruturais dos países da América Latina, mas focalizar, destacar, a prática de políticas e programas compensatórios, ou considerados prioritários pelos governos de turno.

Vale observar que, nos textos publicados pelo BID/INDES, a expressão usual era gerencial social, embora em algumas referências bibliográficas aparecesse a expressão gestão social. Vejamos algumas dessas referências. Em praticamente todo o livro "Gerencial social en América Latina", de 2002, organizado por Isabel Licha, a expressão dominante é gerência social. No entanto, em sua parte III surge o título "Programa de apoio a la gestión social en Brasil", de um texto escrito por brasileiros, que descreve a implantação no país do supracitado programa:

En julio de 1966 se inició la elaboración del Programa de Apoyo a la Gestión Social que tiene por objeto mejorar la eficiencia y la eficacia de los programas sociales prioritarios de Brasil, de esa manera, lograr una transformación profunda en la forma como estos programas sociales llegan a la mayoría de la población” (Licha, 2002, p. 170).

Também é possível verificar o emprego simultâneo das expressões "gerência social" e "gestão social" no livro "La gerencia social ante los nuevos retos del desarrollo social en América Latina", organizado por Fábian Repetto, cujo capítulo 2 tem o seguinte título: "La dimensión cultural en la gestión social. El papel de la gerencia social y la construcción de ciudadanía plural en América Latina” (Repetto, 2005, p. 101). Embora em todos os textos e documentos publicados pelo BID/INDES a expressão usual tenha sido "gerencial social", nos livros citados, apenas para mencionar dois exemplos, fica a dúvida: a expressão gerência social seria sinônimo de gestão social? No léxico castelhano, "gerencia" difere do português apenas pelo fato de colocarmos na língua lusitana o circunflexo no segundo "e", "gerência"; o mesmo com "gestión" em castelhano e "gestão" em português.

Por sua vez, o conceito de gestão social em alguns espaços da academia brasileira, como era o caso da EBAPE, passou a significar o processo gerencial a ser compartilhado pelos diferentes sujeitos sociais nele envolvidos, ou seja, desde então (1990), gestão social não era o mesmo que gerência social. Acrescente-se a isso o fato de que distinguíamos o significado de gestão social do conceito de gestão estratégica, distinção que não fazia parte do vocabulário daqueles que utilizavam a expressão "gerência social" como importante à implementação de políticas compensatórias. Em nossa visão, havia uma confusão conceitual, pois alguns de seus textos utilizam as expressões "estratégia" e "gestão estratégica" como instrumentos da gerência social. Podemos encontrar um exemplo bem explícito em um dos Documentos de Trabajo I-56 (2006) do INDES, elaborado por dois professores do instituto, Karen Mokate e José Jorge Saavedra: "Gerencia social: un enfoque integral para la gestión de políticas y programas”. Nele, em dois itens capitulares, encontram-se: "Seis desafios de la acción estratégica de la gerencia social" (p. 8) e "Un marco conceptual de estrategia y gestión estratégica para la gerencia social” (p. 19). Seria uma contradição de termos? Um oxímoro? Diversos poderiam ser os argumentos com os quais os referidos professores explicariam a interação ou correlação das palavras estratégia e gestão estratégica com gerência social. No entanto, repetimos, desde 1990 fazemos a distinção entre gestão social e gestão estratégica. Nossa explicação deriva do referencial teórico que adotamos para expor a distinção de ambos os conceitos. Aparentemente, o mesmo não ocorria com as referências utilizadas pelos referidos professores do INDES e outros.

Portanto, parece que as diferenças conceituais entre gestão social e gestão estratégica não eram consideradas. Os motivos poderiam ser diversos. Um deles poderia estar vinculado ao fato de que naqueles anos 1990 a expressão estratégia estava “in”, ou seja, em qualquer que fosse o assunto a expressão deveria estar presente - talvez por modismo? Outro motivo poderia ser o uso inconsciente dos referenciais teóricos, ou, talvez, os autores que escreviam sobre gerência social desconhecessem as publicações que no Brasil já 
discorriam, à época, sobre gestão social - o que justificaria o que disse Darcy Ribeiro sobre estarmos, na América Latina, de costas uns para os outros.

Vale relembrar que no período FHC, notadamente em seu primeiro mandato, dois programas voltados à modernização gerencial do serviço público pareciam não caminhar juntos, pois não convergiam. Um desses programas acontecia a partir do Plano Diretor da Reforma do Aparelho do Estado, implementado pelo então Ministério da Administração Federal e da Reforma do Estado e que tinha como uma de suas preocupações pôr em prática aquilo que na época era chamado de administração pública gerencial, ou nova administração pública. Simultaneamente a um dos objetivos do Plano Diretor (visando a melhoria da capacidade gerencial dos servidores públicos da União na sua aproximação com a sociedade ou com o que denominava de cidadãousuário, ou cidadão-cliente) ${ }^{[x v i]}$ caminhava o Programa de Apoio à Gestão Social no Brasil, que, como já observado, inicia suas ações em 1996 com o objetivo de melhorar o desempenho gerencial dos diferentes programas sociais patrocinados pelo governo FHC.

Por que eles pareciam caminhar sem convergir? Porque, se de um lado o Plano Diretor tinha a preocupação de melhorar o desempenho da burocracia estatal por meio da nova administração pública, tinha também como uma de suas características transferir "para o setor público não estatal [os] serviços sociais e científicos competitivos" (Pereira, 1998, p. 81). Assim, parecia que o Programa de Apoio a Gestão Social repetia a necessidade de uma capacitação gerencial para os novos tempos, mas estava direcionado à melhoria gerencial dos programas sociais considerados prioritários pelo governo. No entanto, o programa corria o risco de "chover no molhado", na medida em que uma série de atividades na área social já não ficariam com o Estado, e sim com "as entidades públicas não estatais (ou seja, usando-se outros nomes como que são designadas, são entidades do terceiro setor, são entidades sem fins lucrativos, são organizações não governamentais, organizações voluntárias)" (Pereira, 1998, p. 67). Por essa razão, passa a ocorrer um fato interessante na academia brasileira: as distintas interpretações do conceito de gestão social. Enquanto algumas instituições de ensino superior (IES) entendiam a gestão social como aquela definida na nota 3 deste artigo, ou seja, um conceito antagônico ao de gestão estratégica (nota 4), outras IES percebiam o mesmo conceito como tendo objeto de aplicação apenas no terceiro setor, isto é, não admitiam a possibilidade da sua prática ser mais abrangente, possível de ser aplicada às organizações do primeiro, segundo e terceiro setor.

Salientemos que no livro "Por uma nova gestão pública" (2005), de Ana Paula Paes de Paula, a autora desenvolve no capítulo 8 o conceito de administração pública societal, que de certa forma contrariava a administração pública gerencial ou o que ela denomina, logo no início da obra, vertente gerencial. Por sua vez, a administração pública societal é designada de vertente societal, que procura desenvolver "formas de organização e administração do Estado que incluem a participação da sociedade, procurando construir uma gestão pública social” (Paula, 2005, p. 23). Na descrição do capítulo 8 do livro de Ana Paula, a gestão social seria uma das possibilidades da vertente societal na qual

buscam-se criar organizações administrativas efetivas, permeáveis à participação popular e com autonomia para operar em favor do interesse público. Trata-se de estabelecer uma gestão pública que não centraliza o processo decisório no aparelho do Estado e contempla a complexidade das relações políticas, pois procura se alimentar de diferentes canais de participação, e modelar novos desenhos institucionais para conectar as esferas municipal, estadual e federal. (Paula, 2005, p. 159).

Embora o estudo de Ana Paula esteja diretamente relacionado à administração pública, portanto, aos limites do aparelho do Estado, recuperamos que a vertente societal aqui definida, a gestão social, não estaria restrita ao setor público, podendo ser aplicada tanto no setor privado quanto no setor público não estatal, como anteriormente frisado. Apesar deste intento de uma gestão democrático-deliberativa, sob o qual poderemos observar experimentos no banco de dados do Programa Gestão Pública e Cidadania, [xxii] alguns outros experimentos desde o primeiro governo Lula (2003) até o golpe parlamentar de 2016, no governo Dilma Rousseff, foram tentativas de operacionalizações não só de políticas públicas, mas também da participação cidadã exercendo o controle social, como foi o caso nos municípios e por meio de preceito 
constitucional, das práticas dos Conselhos Gestores Municipais e de outros arranjos institucionais que transitavam do local ao central nas esferas de governos.

Convém aqui explorar melhor o que entendemos como processo do golpe parlamentar para compreendermos, mais adiante, o quanto tal evento transformou-se numa ameaça para as conquistas democráticas e para a Gestão Social, uma vez que o espaço democrático no sentido amplo, não apenas direito de voto, é vital para que os diferentes interesses sociais expressem suas demandas e preferências. Fernando Limongi (2017), citando Pèrez-Liñan, afirma que "o impeachment é frequentemente uma arma institucional empregada contra presidentes que enfrentam um legislativo beligerante".

Tal beligerância aparece fortemente no período após o ano de 2014 por intermédio de embates liderados pelo então presidente da Câmara dos Deputados, Eduardo Cunha. Primeiro, como veremos mais adiante, por meio de uma conspiração parlamentar demonizando o Decreto-Lei que instituía a Política Nacional de Participação Social (PNPS). Nessa contenda, o termo "participação" era tratado por parcela da classe política e da mídia, como manipulação da esquerda. A eclosão e a repercussão de escândalos de corrupção, com grande cobertura midiática, deterioraram a base de apoio parlamentar, abrindo caminho para o que Limongi denominou como momento em que "os partidos 'trânsfugas' não estavam simplesmente abandonando o governo. Estavam mudando de lado, passando a apoiar um governo alternativo". O impeachment, ou o golpe parlamentar, estava em curso contra o governo e em confronto com parte das conquistas democráticas. Tal processo corrobora com a tese do golpe defendida por Jessé de Souza (2016) e, como apontado por Feres e Sassara (2016), que tal processo decorreu de vários fatores e também contou com o protagonismo da grande mídia que acabou "promovendo Moro e os promotores de Curitiba à condição de heróis nacionais, pressionando ministros do Supremo à ação e à inação, conclamando às ruas massas de classe média das grandes cidades". Todavia, é Limongi (2017, p. 6) que destaca o protagonismo parlamentar na derrubada de Dilma Rousseff ao afirmar que "Ninguém disputa este fato: o deputado Eduardo Cunha, então presidente da Câmara dos Deputados, foi o grande artífice da operação que apeou Dilma do poder”.

A questão que nos direciona para o seguinte item deste artigo é: até que ponto, após o golpe parlamentar de 2016, faz sentido o conceito de gestão social à contemporaneidade brasileira?

\section{GESTÃo SOCIAL: CONTEXTO CONTEMPORÂNEO}

Tratando especificamente do contexto anterior a 2016, Pinho (2010) questionava a possibilidade da prática da gestão social no Brasil. Apesar de ser um texto denso e criativo a ponto de alguns dos itens serem intitulados "Gestão social: que animal é esse?”, “Contra-argumentando: um freio de arrumação" e "Caindo na (dura) realidade empírica”, vale a pena transcrever um de seus parágrafos conclusivos:

Uma terceira crítica aqui esboçada se pretende à construção de uma alternativa a este modelo a partir de uma gestão social ancorada na ideia da democracia deliberativa onde o papel da participação popular se torna vital. Neste caso, substanciamos nossa crítica à impossibilidade e inviabilidade desta alternativa às condições estruturais da formação social brasileira onde não se identifica uma sociedade civil vigorosa e ativa, tanto pelo peso da trajetória histórica da nossa formação onde o Estado tem um papel decisivo quanto por características dessa própria sociedade civil, que precisaríamos de mais espaço para explorar. Identificamos como fundamental para viabilizar essa participação o acesso à conhecimentos que só a educação pode proporcionar (Pinho, 2010, p. 50).

Pinho tem razão quando enaltece a importância da educação. Contudo, não devemos esperar que todo um processo de educação formal alcance toda a sociedade para que possamos fomentar processos participativos. Paulo Freire, no seu livro "Extensão ou comunicação", comenta que o processo de extensão, aqui estendido a práticas da gestão social, é educativo e dialógico "com aqueles que, quase sempre, pensam que nada sabem, para que estes, transformando seu pensar que nada sabem em saber que pouco sabem, possam igualmente saber mais (Freire, 1983, p. 25). Ou seja, praticantes de gestão social devem ir a "campo" sabendo que detêm um conhecimento, mas que aqueles que o receberão também possuem um conhecimento, uma prática, uma 
vivência de mundo que deve ser respeitada. Portanto, o processo dialógico é a tônica, desde sempre, do conceito de gestão social.

$\mathrm{Na}$ mesma publicação referenciada a Pinho em 2010, Fernando Tenório escreveu "Gestão social: uma réplica” e comenta que não tem "a intenção de polemizar com o refutante, não só para 'não perder o amigo', mas, principalmente, porque considero a sua atitude saudável, uma vez que levo em conta que o ambiente acadêmico é o espaço institucional necessário, porém não suficiente, para a promoção da dúvida" (Tenório, 2010, p. 53). Já caminhando às suas conclusões, vai dizer:

Assim, o nosso entendimento sobre o conceito de gestão social não está restrito àquele utilizado como referência pelo Prof.
Pinho na sua controvérsia, mas por meio de um processo de aprendizado dialético negativo, ou seja, sem nenhuma pretensão
de síntese conceitual, uma vez que o tema carece de debates que o justifiquem como um processo de gestão que transcenda
aquele demarcado apenas pelo mercado, a gestão estratégica. O intento de demarcar um novo marco conceitual - gestão
social, tem a pretensão tão somente de enfatizar a necessidade de que os gestores, qualquer que seja a configuração jurídica da
organização, atuem sob uma perspectiva na qual o determinante de suas ações deve ser a sociedade e não o mercado" (Tenório,
2010, p. 57).

Quanto ao determinante ser a sociedade e não o mercado, valemo-nos da crítica que Alberto Guerreiro Ramos faz ao determinismo de mercado nos estudos organizacionais, uma vez que é desse determinismo mercado - que o conceito de gestão social procura escapar, dado que este é um conceito que circula no âmbito de uma ciência social aplicada, a Administração:

A política cognitiva é a moeda corrente psicológica da sociedade centrada no mercado. Não constitui mero incidente o fato
de que, em toda sociedade em que o mercado se transformou em agência cêntrica da influência social, os laços comunitários
e os traços culturais são solapados ou mesmo destruídos. (...) Aqui estou eu simplesmente chamando a atenção para o óbvio,
mas é precisamente o óbvio que constitui propósito da política cognitiva obscurecer. Esse evento praticamente universal,
resultante do expansionismo político das sociedades hegemônicas centradas no mercado, élegitimado como princípio básico
da ciência social contemporânea (Guerreiro Ramos, 1981, p. 90).

Em 2012 Tenório publicou no livro "Gestão social: aspectos teóricos e aplicações", organizado por Cançado et al., o texto "Gestão social, um conceito não idêntico? Ou a insuficiência inevitável do pensamento", no qual não segue mais refutando Pinho, reconhecendo, contudo, que a concepção e (ou) vida histórica de qualquer proposta teórica ou conceitual na medida em que tais concepções não guardam identidade com a realidade, fato que parece estar acontecendo na atualidade brasileira não só com o conceito de gestão social assim como com todas aquelas propostas teóricas que proponham uma sociedade socialmente justa e democraticamente orientada. Desse modo, comenta Tenório:

Assim, o não idêntico se mantém negativo e contra toda pretensão de identidade, também não idêntico consigo mesmo.
O conceito de gestão social, portanto, não está presente na realidade. Esta não representatividade é o que constitui a
substância da gestão social na medida em que permanece dispersa e incerta nas suas pretensões. Apesar disso, o fato não
sugere que não procuremos defini-lo, todo objeto de estudo deve ser explicitado, até porque o tema tem-se constituído [até
a presente data] não só objeto de estudo, mas, também, como caracterização profissional, haja vista o número de cursos
criados como esse objetivo, quer como especialização, quer como formação em Graduação, Mestrado e Doutorado. O que
parece manifestar que a sociedade carece de um tipo profissional que dê conta não apenas da gestão racional instrumental
dessa mesma sociedade, mas, da mesma forma, de profissionais sensíveis a outras racionalidades promotoras de um bem-estar
fundamentado na justiça social e não apenas na conformidade do mercado" (Tenório, 2012, p. 33).

Como poderíamos tornar contemporâneo um conceito que vai de encontro à contemporaneidade vigente no país? Esta não é uma simples descrição dialética, é uma realidade posta em questão desde 2016, quando um golpe parlamentar destituiu da presidência Dilma Rousseff. Até então, e principalmente desde o primeiro governo Luiz Inácio Lula da Silva, o conceito de gestão social vinha sendo discutido na academia e posto em prática por meio de políticas públicas implementadas em seus mandatos. Sem exagero, poderíamos dizer que certo ufanismo parecia ser o futuro de uma nova institucionalização para o Brasil com respeito à possibilidade da prática de uma gestão democrático-deliberativa, compartilhada de modo 
intraorganizacional, ou entre atores sociais e agentes econômicos, ou, ainda, entre atores sociais e poderes públicos, isto é, a possibilidade de uma cidadania ativa, atuante, inclusive de viés com controle social. No entanto, surge na História uma circunstância que desmonta aquilo para o que foi elaborada a Constituição de 1988, a condição de que seria possível um povo viver de forma democrática em busca da justiça social. Utopia? Com o golpe de 2016 um processo distópico começa a ser engendrado, acentuando-se em 2019 com a ascensão ao poder central o governo de Jair Messias Bolsonaro. Portanto, a Constituição de 1988 de significante passa a não ter mais significado. Como isso ocorre?

Parece que o processo distópico não começou apenas com a ascensão do governo Bolsonaro ao poder em 2019. Em junho de 2013, inicia-se um movimento social no país que reclama do aumento de passagens de ônibus na cidade de São Paulo. Chega a 2015 com manifestações ampliadas, embora difusas, contra o governo Dilma Rousseff e, obviamente, tudo que fosse originado no Partido dos Trabalhadores (PT), culminando no golpe jurídico-parlamentar em agosto de 2016. Esse golpe "foi caracterizado como 'parlamentar', 'judicial', 'midiático', 'empresarial' ou ainda uma combinação destes adjetivos” (Miguel, 2019, p. 112). Essa mobilização social, cuja composição variava da extrema esquerda à extrema direita, poderia estar inserida na "desdemocratização", na qual "a democracia que se construiu nos países do Ocidente ao longo do século XX sempre ficou muito aquém do ideal de governo do povo. Ainda assim, representava a promessa de incorporação da maioria da população na cena política e a possibilidade de que seus interesses fossem levados em conta nos processos de tomada de decisão" (Miguel, 2019, pp. 113-114).

O Brasil vinha experimentando maior protagonismo social nas decisões governamentais desde o período anterior a 1988, com o surgimento de movimentos sociais que dividiam suas ações entre processos reivindicatórios - moradia, saúde e creche, entre outras demandas - e promoviam açóes contra o regime militar, organizando manifestações pela democracia mesmo nos anos de chumbo da ditadura (Sader, 2001). As pressões de tais movimentos tinham característica local: cobravam de prefeitos respostas aos seus anseios e abriam canais de diálogo com várias prefeituras. Foi assim que nasceram programas de administração participativa em pequenos municípios como Icapuí, no Ceará, Janduís, no Rio Grande do Norte (Almeida, 1993), e Lages, em Santa Catarina (Souto, 1991), entre outros.

Nesses locais, a gestão municipal discutia as prioridades na alocação de recursos com as comunidades e prestava contas de seus gastos, publicando a execução orçamentária em local aberto à população. Era uma iniciativa de orçamento participativo com políticas de transparência, sem que ainda se tivesse o sentido que esses termos possuem nos dias hoje.

Esses processos participativos influenciaram a elaboração da Carta Magna de 1988. A nova Constituição Federal nasceu prevendo a abertura de instrumentos de participação social no orçamento e nas políticas públicas, como a realização de audiências públicas e a criação de conselhos gestores de políticas públicas. Constitucionalizou-se direitos sociais e promoveu uma saudável combinação entre instrumentos da democracia representativa e da democracia direta, como plebiscito, referendo e iniciativa popular.

Tais mecanismos de participação, que permeou vários processos de democratização das políticas públicas, possibilitando a participação cidadã no desenho da implementação das mesmas em muitos casos, ocorriam em governos municipais estimulados por decisão política dos chefes do Executivo. Experiências de Orçamento Participativo como as de Porto Alegre, Recife e Belo Horizonte, para falar em algumas grandes capitais, transformaram-se em vitrines de governos de esquerda.

No âmbito federal, as grandes conferências de saúde, educação, segurança alimentar, assistência social, entre outras, mobilizaram representantes de segmentos sociais de diversas regióes do país, que possibilitaram o redesenho de políticas públicas nessas áreas. Ao que tudo indica, a última grande mobilização social que se transformou numa legislação que ampliou a democracia e garantiu acesso a direitos pelos cidadãos foi a Conferência Nacional de Transparência e Controle Social. Apoiada pelo governo federal por meio do envolvimento direto da Controladoria-Geral da União (CGU), a conferência culminou na aprovação da nova Lei de Acesso à Informação (Lei n. 12.527/2011) durante o governo Dilma Rousseff (Loureiro et al., 
2012), porém, o enfraquecimento dos espaços públicos de democracia no Brasil começa um pouco antes de 2016 e por reação de uma maioria parlamentar conservadora na Câmara dos Deputados, que resolveu investir contra os espaços participativos, alegando que usurpavam atribuiçóes do Legislativo.

Durante o governo Dilma, a então presidente da República baixou o Decreto n. 8.243/2014, criando a Política Nacional de Participação Social (PNPS). O objetivo não era criar novos processos participativos, pois estes já existiam. O problema que se buscava resolver era a falta de arcabouço legal que institucionalizasse o processo. Com parte dos movimentos de 2013 ainda nas ruas pressionando contra a realização da Copa do Mundo no Brasil e desgastando politicamente o governo, além de ser ano eleitoral, 2014 talvez não fosse o momento adequado para a viabilização desse decreto. A proposta foi anulada pela Câmara dos Deputados logo após Dilma Rousseff vencer Aécio Neves em segundo turno da disputa presidencial mais tensa e polarizada desde a redemocratização. A diferença percentual de votos entre a vencedora e o derrotado foi de pouco menos 1,7\%.

Aécio Neves adotou uma postura nociva à democracia ao levantar suspeita de fraude e afirmar que "perdi a eleição para uma organização criminosa que se instalou no seio de algumas empresas brasileiras patrocinadas por esse grupo político que aí está". O Tribunal Superior Eleitoral (TSE) rechaçou as suspeitas de fraude. Todavia, a fala de Aécio estimulou grupos extremistas a iniciarem campanha pelo processo de impeachment. O grau de criminalização da política e da democracia ampliava-se no Brasil.

Um novo ataque aos espaços formais de participação no Brasil foi deferido pelo presidente Jair Bolsonaro em abril de 2019. Por meio do Decreto-Lei 9.759/2019 extinguiu cerca de 700 conselhos, comitês, comissões, grupos e outros tipos de colegiados como o Comitê Gestor da Internet no Brasil e o Conselho Nacional de Enfrentamento ao Tráfico de Pessoas. Tal medida foi declarada parcialmente inconstitucional pelo STF em 13/06/2019, o que tornou quase todo o Decreto sem efeito. Entretanto, o discurso de que tais conselhos atrapalham e impedem decisões continua pairando como uma ameaça a esses espaços participativos.

A desinstitucionalização da democracia, ainda que no Brasil a democracia estivesse em processo naquele período, isto é, uma nova institucionalidade "desdemocratizante", vai de encontro aos anseios de uma cidadania ativa inerente aos anseios de uma gestão compartilhada, de uma gestão social, e essa desinstitucionalização vai ao encontro da "noção de semicidadania, [que] descreve as realidades plurais e diversas de vários grupos e indivíduos que vivem em democracias liberais hoje em dia, mas não têm acesso a todo o pacote de direitos de cidadania" (Maia \& Pontin, 2019, p. 154), como desejaríamos. Portanto, essa "semicidadania" ou quase-cidadania não caracteriza a possibilidade de uma cidadania participante do processo de tomada de decisão, no qual os diferentes atores sociais, oriundos do poder público, dos agentes econômicos (mercado) e das organizações da sociedade civil, dialoguem e deliberem, por meio de uma gestão compartilhada, dialógica, os destinos da sociedade ou de interesses de seus enclaves.

O que apontamos neste texto é o desejo de uma prática gerencial que atenda aos seguintes valores normativos originados ainda no século XVIII: igualdade: "[e]m uma sociedade justa, todas as pessoas teriam amplo e igual acesso aos meios materiais e sociais necessários para viver uma vida plena” (W right, 2020, p. 33, itálicos do autor); liberdade: "[e]m uma sociedade totalmente democrática, todos teriam amplo e igual acesso aos meios necessários de participar na tomada de decisóes substantivas sobre aquilo que afeta suas vidas" (Wright, 2020, p. 38, itálicos do autor); solidariedade: "expressa o princípio pelo qual as pessoas devem cooperar umas com as outras não apenas por aquilo que recebem individualmente, mas por comprometimento real com o bemestar dos outros e por um senso de obrigação moral de que isso é o certo a ser feito" (Wright, 2020, p. 41, itálicos do autor).

Quando falamos de democracia e de processos participativos, salientamos que essas práticas devem ocorrer em uma sociedade democrática na qual o controle social deve ser feito pelas pessoas e não apenas pelas instituições formais, porque em "uma sociedade democrática (em vez de um Estado democrático), implica muito, mas que isso; exige que as pessoas possam participar, de forma significativa, em toda e qualquer decisão 
que afete suas vidas, sejam elas tomadas pelo Estado, sejam elas tomadas por outras instituições [inclusive aquelas do mercado e da sociedade civil]" (Wright, 2020, p. 39). Dessa maneira,

[o]s valores igualdade/justiça, democracia/liberdade e comunidade/solidariedade são relevantes para que possamos avaliar qualquer instituição ou estrutura social. Famílias, comunidades, religióes, escolas e Estados, bem como sistemas econômicos, todos podem ser analisados por meios desses termos para que possamos entender se eles obstruem a realização desses valores. Da mesma forma, ao pensarmos em alternativas, devemos julgá-las com base nesses valores (Wright, 2020, p. 44).

\section{CONSIDERAÇÕES FINAIS}

Como os leitores devem ter observado desde o início do texto, várias são as contradições que o permeiam. A primeira está na não prática contemporânea dos cânones constitucionais de 1988, na medida em que lideranças do quadro burocrático brasileiro nos três poderes - Executivo, Legislativo e Judiciário - e nos três níveis de governo - federal, estadual e municipal - tomam e praticam decisões de modo não republicano. Secunda esta primeira contradição, no caso do nosso tema, pelo contraponto entre gestão social e gestão estratégica. Esse contraponto privilegia, de modo consciente ou inconsciente, práticas gerenciais que contribuem para aumentar a distância entre o Estado e a sociedade, exercitando uma "nova gestão pública" caracteristicamente pré-burocrática. Portanto, todas as iniciativas encetadas nos anos 1990 para a modernização da administração pública brasileira ficaram nos arquivos de sua história.

Desse modo, porém lamentando, aceitamos o pensamento adorniano quando diz que "[toda] determinação que se apresenta como desprovida de contradição se revela tão contraditória quanto os modelos ontológicos ser e existência" (Adorno, 2009, p. 127). "A hybris[xxxii] [a arrogância] consiste em querer que a identidade seja, que a coisa corresponda em si ao seu conceito" (Adorno, 2009, p. 130).

Assim, a possibilidade de que no Brasil contemporâneo sejam possíveis práticas de uma gestão articulada entre os seus concernidos, entre os seus interessados, que as coisas possam ser processadas segundo os preceitos constitucionais de 1988, poderia ser uma ingênua e descontextualizada arrogância acadêmica, ou apenas uma utopia, porque "[a]s ideias vivem nas cavernas existentes entre aquilo que as coisas pretendem ser e aquilo que elas são. A utopia estaria acima da identidade e acima da contradição" (Adorno, 2009, p. 131), portanto, o conceito de gestão social poderá ter tido a sua culminância utópica correspondente ao tempo de uma geração. Pode ter sido, acompanhando o pensamento de Erik Olin Wright, uma utopia real (Wright, 2020), ou, como no dizer de Vladimir Safatle (2016), "[não] precisamos reinstaurar o tempo das utopias. Precisamos, na verdade, ter uma visão mais complexa das tensões e tendências que operam no presente e compreender as latências de transformação que nos habitam" (Safatle, 2016, p. 305).

Quando cotejamos o contexto brasileiro após o ano de 2016 com o conceito de gestão social, fica latente o distanciamento entre o conceito e os rumos assumidos pela gestão pública brasileira em âmbito nacional. Como vimos, existe por parte do governo federal empossado em 2019 uma clara tentativa de extinguir espaços democráticos ou mesmo sufocá-los, tirando-lhes recursos. Estamos diante de um retrato e não ainda não vislumbramos qual será o final desse filme. Uma boa contribuição para estudos futuros seria desenvolver uma agenda de pesquisa combinando investigações acerca dos mecanismos de participação social e sua efetividade por área de políticas públicas frente ao ambiente de regressão democrática pós 2016. Isso nos ajudaria a avançar na compreensão sobre as possibilidades de uma gestão pública efetivamente democrática no atual contexto brasileiro, mesmo diante das várias incertezas sociais, econômicas e políticas, que derivam da Covid-19.

\section{REFERÊNCIAS BIBLIOGRÁFiCAS}

Adorno, T. W. (2009). Dialética negativa. Rio de Janeiro: Editora Jorge Zahar. 
Aguiar-Barbosa, A. P., \& Chim-Miki, A. F. (2020). Evolução do conceito de gestão social (1990-2018): uma análise de copalavras. Cadernos de Gestão Pública e Cidadania, 25(80), 1-22.

Almeida, M. A. (1993). Estudos de gestão: Icapuí e Janduís. São Paulo: Instituto Pólis.

Andrews, C. W., \& Kouzmin, A. (1998). O discurso da nova administração pública. Lua Nova, 45(1), 97-129.

Brasil, Constituição (1988). Constituição: República Federativa do Brasil. Brasília: Senado Federal, Centro Gráfico.

Bloch, E. (2005). O princípio esperança. Rio de Janeiro: EdUERJ - Contraponto.

Cohen, E., \& Franco, R. (2005). Gestión social: cómo lograr eficiencia e impacto en las políticas sociales. México (DF): Siglo XXI Editores/CEPAL.

Cançado, A. C. et al. (Orgs.). (2012). Gestão social: aspectos teóricos e aplicações. Ijuí: Editora UNIJUÍ.

Di Giovani, G., \& Nogueira, M. A. (Orgs.) (2015). Dicionário de políticas públicas. São Paulo: Editora da UNESP Fundap.

Feres, J. Jr., \& Sassara, L. O. (2016). O terceiro turno de Dilma Rousseff. Saúde em debate, 40(special), 176-185.

Freire, P. (1983). Extensão ou comunicação? 7. ed. Rio de Janeiro: Editora Paz e Terra.

Guerreiro Ramos, A. (1981). A nova ciência das organizações: uma reconceituação da riqueza das nações. Rio de Janeiro: Editora FGV.

Licha, I. (Org.). (2002). Gerencia social en América Latina. Washington (DC): Banco Interamericano de Desarrollo.

Limongi, F. (2017). Impedindo Dilma. Novos estudos CEBRAP, Especial, 5-13.

Linera, Á. G. (2015). Forma valor y forma comunidad. Quito: IAEN.

Loureiro, M. R. et al. (2012). Do controle interno ao controle social: a múltipla atuação da CGU na democracia brasileira. Cadernos Gestão Pública e Cidadania, 17(60), 2236-5710.

Maia, T. V, \& Pontin, F. (2019). Cidadania, semi-cidadania e democracia no Brasil contemporâneo. In PinheiroMachado, R, \& Freixo, A (Orgs.). Brasil em transe: bolsonarismo, nova direita e desdemocratização. Rio de Janeiro: Oficina Raquel, pp. 144-160.

Miguel, L. F. (2019). Há solução sem uma revolução? In Pinheiro-Machado, R, \& Freixo, A (Orgs.). Brasil em transe: bolsonarismo, nova direita e desdemocratização. Rio de Janeiro: Oficina Raquel, pp. 99-119.

Mokate, K, \& Saavedra, J. J. (2006). (Documento de Trabajo I-56) Gerencial social: enfoque integral para la gestión de politicas y programas. Washington (DC): DIPR/INDES/BID.

Paula, A. P. P. (2005). Por uma nova gestão pública: limites e potencialidades da experiência contemporânea. Rio de Janeiro: Editora FGV.

Pereira, L. C. B. (1998). A reforma do Estados dos anos 90: lógica e mecanismo de controle. Lua nova, 45(1), 49-98.

Pinho, J. A. G. (2010). Gestão Social: conceituando e discutindo os limites e possibilidades reais na sociedade brasileira. In Rigo, A. S. et al. Gestão social e políticas públicas de desenvolvimento: açôes, articulaçôes e agenda. Recife: Univasf, pp. 21-52.

Repetto F. (2005). (Org.). La gerencia social ante los nuevos retos del desarrollo social en América Latina. Ciudad de Guatemala: Magna Terra Editores S.A.

Saad, A. Filho (2018). Brasil: neoliberalismo versus democracia. São Paulo: Boitempo.

Sader, E. (2001). Quando os novos personagens entram em cena: Experiências, falas e lutas dos trabalhadores da Grande São Paulo, 1970-80. 4. ed. Rio de Janeiro: Editora Paz e Terra.

Safatle, V. (2016). Viver sem esperança é viver sem medo ou contra a utopia. In Novaes, A. (Org.). O novo espirito utópico. São Paulo: Edições SESC SP.

Schwarz, L. M. (2019). Sobre o autoritarismo brasileiro. São Paulo: Companhia das Letras.

Souza, J. A. (2016). Radiografia do golpe: entenda como e por que você foi enganado. Rio de Janeiro: Editora Leya.

Souto, A. L. S. (1991). Lages: um jeito de governar. São Paulo: Instituto Pólis.

Tenório, F. G. (2010). Gestão social: uma réplica. In Rigo, A. S. et al. Gestão social epolíticaspúblicas de desenvolvimento: ações, articulaçôes e agenda. Recife: Univasf. 
Tenório, F. G. (2012). Gestão social, um conceito não idêntico? Ou a insuficiência inevitável do pensamento. In Cançado, A. C. et al. (Orgs.). Gestão social: aspectos teóricos e aplicações. Ijuí: Editora Unijuí.

Tenório, F G. (2016). Uma alternativa: gestão social. Ijuí (RS): Editora Unijuí.

Wright, E. O. (2020). Como ser anticapitalista no século XXI? São Paulo: Editora Boitempo.

\section{Notas}

[i]A gestão social é a tentativa de "substituir a gestão tecnoburocrática, monológica, por um gerenciamento participativo, dialógico, no qual o processo decisório é exercido por diferentes sujeitos sociais. Em seu processo de afirmação, a verdade só existe se todos os participantes da ação admitem sua validade, isto é, a verdade é a promessa de consenso racional, não é uma relação entre o indivíduo e sua percepção de mundo, mas sim um acordo alcançado por meio da crítica intersubjetiva" (Di Giovanni \& Nogueira, 2015, p. 412).

[ii] Gestão estratégica seria "um tipo de ação social utilitarista, fundada no cálculo de meios e fins e implementada mediante a interação de duas ou mais pessoas, na qual uma delas tem autoridade formal sobre a(s) outra(s). Por extensão, esse tipo de ação gerencial seria aquele no qual as organizações empresariais privadas determinariam suas condições de funcionamento e o Estado se imporia à sociedade por meio de processos eminentemente fundados na técnica, configurando intervenções de caráter tecnocrático" (Di Giovanni \& Nogueira, 2015, p. 412).

[iii] “Embora sejam objeto de diferentes interpretações, os termos cidadão e cidadania geralmente remetem ao indivíduo pertencente a uma comunidade e portador de um conjunto de direitos e deveres" (Di Giovanni e Nogueira, 2015, p. 135, itálico dos autores). "Como sintetiza Norberto Bobbio (...), a cada categoria de direitos corresponde uma concepção de liberdade: os direitos civis reservam ao indivíduo uma esfera de liberdade em relação ao Estado; os direitos políticos lhe garantem a liberdade no Estado; e os direitos sociais significam liberdade por meio do Estado" (Di Giovanni \& Nogueira, 2015, p. 412, itálico dos autores).

[iv] “Democracia representativa é a forma de governo em que os cidadãos - isto é, os titulares do poder na comunidade política - não exercem sua soberania diretamente, mas a delegam a representantes eleitos, ou seja, a autoridades escolhidas em eleições livres, periódicas, competitivas, regulares, definidas por lei e monitoradas por um corpo judicial independente" (Di Giovanni \& Nogueira, 2015, p. 252).

[v]"A democracia deliberativa é definida como resultante da decisão coletiva que emerge de arranjos que agregam escolhas coletivas estabelecidas em condições de livre e pública argumentação entre iguais, governados por essas decisões" (Di Giovanni \& Nogueira, 2015, p. 239).

[vi] "[A] Constituição de 1988 deixou frestas abertas. Ela deixou intocada a estrutura agrária, permitiu a autonomia das Forças armadas (...), manteve inelegíveis os analfabetos - embora tenha aprovado seu direito de voto. Preservou igualmente a centralização do Executivo, produzindo-se um Estado agigantado, (...) [assim como] uma concentração de poderes na esfera judicial, desorganizando o equilíbrio que devem imperar entre os três poderes representativos da nação. (...) A despeito desses 'poréns', a Constituição de 1988 continua sendo a melhor expressão de um Brasil que firmou um sólido compromisso democrático em vários níveis das relações sociais, bem como estabeleceu políticas maduras de defesa dos direitos humanos. Ela é atenta às minorias políticas, avançada nas questões ambientais, empenhada em prever meios e instrumentos constitucionais legais para a participação popular direta" (Schwarcz, 2019, pp. 232 - 233).

[vii]No capítulo IV DOS DIREITOS POLÍTICOS da Constituição de 1988, reza o art. 14. "A soberania popular será exercida pelo sufrágio universal e pelo voto direto e secreto, como valor igual para todos, e, nos termos da lei mediante: I - plesbicito; II - referendo; III - iniciativa popular" (Brasil, Constituição, 1988, p. 18). "Por outro lado, desde as revoluções do século 18 (...) a ideia de soberania popular cresce. No limite, ela leva a uma vaga e difusa convicção de que há soberania nacional quando a exerce o povo, em eleições livres e democráticas" (Di Giovanni \& Nogueira, 2015, p. 949).

[viii]Até então, à sigla EBAP não tinha sido acrescentado o "E" de empresas, fato ocorrido em 1990, quando passou a ser denominada de Escola Brasileira de Administração Pública e de Empresas (EBAPE).

[ix] No primeiro período do governo Fernando Henrique Cardoso (1995-1998), com recursos do BID, foi implementado no Brasil o Programa de Apoio à Gestão Social.

[x]Leopoldo Alves Junior, Vera Lucia Amorim Jatobá e Eurídice Nóbrega Vidigal. 
[xi]Na ocasião da implementação do Programa de Apoyo a la Gestión Social no Brasil, foi criada a Rede de Articulação Social e uma página na web: redesocial.org.br.

[xii]Ver nota 3.

[xiii] Ver nota 4 .

[xiv]Referência bibliográfica que contém ensaios que tratam do tema desde os anos 1990: Tenório, Fernando G. (2016). Uma alternativa: gestão social. Ijuí (RS): UNIJUÍ.

[xv]Podemos observar essa aparente contradição de termos em Cohen, Ernesto, \& Franco, Rolando. (2005). Gestión social: cómo lograr eficiencia e impacto en las políticas sociales. México (DF): Siglo XXI Editores/CEPAL.

[xvi]Pelo menos duas referências poderão ser consultadas a respeito do Plano Diretor da Reforma do Aparelho do Estado: bresserpereira.org.br, ou Pereira, Luiz Carlos Bresser. (1998). A reforma do Estados dos anos 90: lógica e mecanismo de controle. Lua nova, 45(1), 49-98 (disponível em: www.scielo.br). Cabe acrescentar que, nesse primeiro período do governo FHC, Luiz Carlos Bresser Pereira ocupava o cargo de ministro da Administração Federal e da Reforma do Estado.

[xvii] Pereira, 1998, pp. 80.

[xviii]Sugerimos duas referências que poderão ampliar a análise sobre o Plano Diretor da Reforma do Aparelho do Estado aqui descrito, de forma pontual, nos dois últimos parágrafos acima desta nota. A primeira referência, por ordem de publicação, é o artigo escrito por Andrews, Christina W., \& Kouzmin, Alexander. (1998). O discurso da nova administração pública. Lua Nova, 45(1), 97-129. A segunda referência é o livro de Paula, Ana Paula Paes de. (2005). Por uma nova gestão pública. Rio de Janeiro: FGV Editora.

[xix]Consultar Aguiar-Barbosa, Amanda, \& Chim-Mik, Adriana Fumi. (2020) Evolução do conceito de gestão social (1990-2018): uma análise de copalavras. Cadernos de Gestão Pública e Cidadania, 25(80), 1-22.

[xx] “[A] vertente gerencial não foi bem-sucedida na abordagem da dimensão sociopolítica, pois ao focalizar a nova administração pública como modelo de gestão, deixou a desejar no que se refere à democratização do Estado brasileiro. Questões que envolvem as relações entre o Estado e a sociedade não foram suficientemente tratadas, permanecendo as características centralizadoras e autoritárias que marcaram a história político-administrativa do país” (Paula, 2005, pp. 23).

[xxi]“[A] vertente societal busca construir e implementar um projeto político capaz de subverter o padrão autoritário das relações entre o Estado e a sociedade no Brasil. Guardando alguns limites, a tentativa de inserir a dimensão sociopolítica em suas experiências de gestão está abrindo possibilidades para a renovação do modelo de gestão pública à medida que traz novas propostas para se repensar as instituições políticas e a dinâmica administrativa” (Paula, 2005, pp. 23).

[xxii]O Banco de Experiências sobre o Programa Gestão Pública e Cidadania, organizado pela Fundação Getúlio Vargas (FGVEAESP) e pela Fundação Ford, com apoio inicial do BNDES, é o resultado de um trabalho de dez anos na identificação de experiências inovadoras de governos estaduais, municipais e de organizações indígenas no Brasil, a partir de uma premiação anual aberta. As atividades continuam hoje por meio de estudos de acompanhamento e avaliação dessas e de outras experiências. Recuperado de https://ceapg.fgv.br/banco-experiencias.

[xxiii]Não devemos esquecer que no ínterim entre 2013 e 2019, principalmente com o governo provisório de Michel Temer, ocorreram vários fatos que contribuíram para demonstrar o processo que mais adiante será denominado de "desdemocratização": suicídio de Luiz Carlos Cancellier, reitor da Universidade Federal de Santa Catarina (UFSC), surgimento da denominada Escola Sem Partido, e tudo aquilo originado no que ficou conhecido como Lava Jato, ação judicial de reclusão que impediu a candidatura, pela terceira vez, de Luiz Inácio Lula da Silva à Presidência da República. Felizmente, em 11 de dezembro de 2018 o projeto Escola Sem Partido foi retirado da pauta da Câmara Federal.

[xxiv]Recuperado de https://www12.senado.leg.br/noticias/materias/2014/11/03/projeto-que-derruba-decreto-da-participaca o-popular-chega-ao-senado em 06.05.2020;

[xxv]Recuperado de https://www.camara.leg.br/noticias/443908-deputados-derrubam-decreto-dos-conselhos-populares/. em 6 maio 2020.

[xxvi]Recuperado de http://g1.globo.com/bom-dia-brasil/noticia/2014/10/dilma-rousseff-e-reeleita-com-545-milhoes-de-voto s-no-segundo-turno.html. em 6 maio 2020. 
Fernando Guilherme Tenorio, et al. O conceito de gestão social e a democracia regressiva no Brasil...

[xxvii]Recuperado de https://josiasdesouza.blogosfera.uol.com.br/2014/12/01/aecio-perdi-eleicao-para-organizacao-criminos a/ em 5 maio 2020 .

[xxviii]Ver https://www.dw.com/pt-br/stf-limita-extin\%C3\%A7\%C3\%A3o-de-conselhos-federais/a-49188650 Recuperado em 20.08.2020.

[xxix]Recuperado de https://g1.globo.com/politica/noticia/2019/07/22/bolsonaro-diz-que-quer-extinguir-a-grande-maioria-d os-conselhos-formados-por-governo-e-sociedade-civil.ghtml em 20.08.2020.

[xxx]"O que consideramos particularmente interessante nessa noção de semicidadania, especialmente quando aplicada ao caso brasileiro, é que ela nos ajuda a visualizar algumas das hierarquias que ainda permanecem em nosso quadro institucional, principalmente aquelas que se alinham com diferenças de gênero e de raça. Se pensarmos na forma como os direitos são concedidos e administrados para a população feminina e não branca no Brasil, podemos ver o reflexo empírico do conceito de semi-cidadania que Cohen está avançando" (Maia e Pontin, 2019, p. 155). Tatiana Vargas Maia e Fabrício Pontin fazem referência ao texto de Cohen, Elizabeth F. (2009). Semi-citizenship in Democratic Politics. Cambridge University Press.

[xxxi] Observar que no livro de Erik Olin Wright, Como ser anticapitalista no século XXI? o autor agrupa esses valores normativos da seguinte forma: "igualdade/justiça, democracia/liberdade e comunidade/solidariedade" (Wright, 2020, pp. 31).

[xxxii]Húbris ou hybris é um conceito grego que pode ser traduzido como "tudo que passa da medida; descomedimento", e que atualmente alude a uma confiança excessiva, um orgulho exagerado, presunção, arrogância ou insolência (originalmente contra os deuses), que com frequência termina sendo punida. Recuperado de https://www.dicionarioinformal.com.br/ em 27 abr. 2020. 